\title{
EL DEVENIR IMPERCEPTIBLE Y LA POLÍTICA DE LA DISCRECIÓN
}

\author{
María del Pilar Gavilanes ${ }^{1}$
}

A partir del concepto del devenir imperceptible planteado por Gilles Deleuze y Félix Guattari $^{2}$, este texto propone una lectura de los planteamientos sobre la discreción como actitud estética y política que el filósofo Pierre Zaoui, cuyo pensamiento se inscribe en la prolongación y el cuestionamiento del trabajo de Gilles Deleuze, desarrolla en su libro La discreción o el arte de desaparecer (2013). Tomando en cuenta las condiciones propias del mundo contemporáneo, Zaoui defiende la discreción como una actitud necesaria en la era del predominio de las apariencias y el exceso de la exhibición mediática.

Retomando las características duales del individualismo moderno, es decir, por un lado el deseo de ser reconocido como individuo libre y, por el otro, el deseo de desaparecer en la multitud de las grandes ciudades, Pierre Zaoui subraya que nuestra modernidad no se caracteriza solamente por una lucha desenfrenada por el reconocimiento y la visibilidad, sino también por una lucha subterránea por el anonimato y la invisibilidad.

Si los medios de masa, las tecnologías de la comunicación y el funcionamiento de las redes sociales promueven la omnipresencia y un máximo de visibilización del individuo y/o de sus perfiles virtuales, La discreción o el arte de desaparecer propone pensar la discreción desde una perspectiva disidente que consistiría en disfrutar de la existencia del mundo y de los otros sin que aquel que percibe deba aparecer y sostener una postura.

De esta manera, la dimensión política de la discreción sería una cuestión de resistencia al orden de la transparencia que pretende identificar al individuo y valorar la existencia bajo el criterio de la visibilidad; la propuesta radicaría, entonces, en retirarse temporalmente del juego de las apariencias y del flujo de las imágenes.

Así, en el mundo contemporáneo, el reto de una política de la discreción consistiría en aprender a dejar el orden de la mostración de sí y de la vigilancia generalizada para devenir imperceptible. Es aquí donde podemos establecer un vínculo con los planeamientos de Deleuze y Guattari. La política de la discreción trataría, básicamente, de una experiencia de despersonalización que no se enfocaría en las identidades, en los seres y las cosas sino en las relaciones que se producen entre ellos.

Volviendo sobre la dualidad establecida entre las apariencias y el desaparecer, Pierre Zaoui señala que la discreción no se opone necesariamente a formas de la política más tradicionales, tomando como ejemplo la forma de las manifestaciones donde se trata a la vez de mostrarse, de demostrar una fuerza por la presencia masiva de voces y de cuerpos y, al mismo tiempo, gozar del anonimato de cada uno como parte de la multitud.

Podríamos relacionar esta voluntad de sustraerse de la luz de los proyectores para regresar a la comodidad del anonimato con personajes literarios y, de manera más específica, con la figura pública del escritor. Así, el exitoso escritor Bill Gray en la novela Mao II (1991) de Don DeLillo, por ejemplo, quien se aísla de la sociedad, no envía noticias a nadie y durante décadas no se publica una fotografía suya. ${ }^{3} \mathrm{El}$ escritor busca escapar del mundo de las imágenes, quiere evitar el convertirse en una imagen, en una mercancía más. Sin embargo, su estrategia para

\footnotetext{
${ }^{1}$ Universidad de las Artes de Guayaquil.

${ }^{2}$ Cf. Deleuze, G. y Guattari, F. Mil Mesetas. Capitalismo y esquizofrenia. Valencia: Pre-Textos, 2002.

${ }^{3}$ Este personaje parecería estar inspirado en las figuras de otros escritores que, a su vez, se sustraen a la esfera pública como J. D. Salinger o Thomas Pynchon, quien desapareció durante casi cuarenta años, además de haber proporcionado poca información sobre su biografía; se podría añadir a esta lista a Suskind o Cormac McCarthy quien rara vez aparece para conceder alguna entrevista, Robert Walser y tantos otros que rehúsan exponerse como personajes públicos.
} 
ocultarse durante décadas produce el efecto inverso pues su ausencia se convierte en un misterio a ser descifrado, su desaparición voluntaria no hace sino contribuir a su mistificación mientras se espera la publicación de su siguiente obra.

Tal vez, es por eso que Bill acepta la llegada de Brita Nilsson a su guarida, una fotógrafa que retrata escritores vivos, conocidos y desconocidos. Este encuentro propiciará el retorno del escritor a la vida de la ciudad donde es nuevamente solicitado como figura pública; un conjunto de circunstancias lo llevarán a vincularse con el caso de Jean-Claude Julian, un joven poeta suizo secuestrado por un grupo terrorista en Beirut, ciudad en la que Bill termina por desaparecer, esta vez, definitivamente.

En esta novela, el personaje del escritor trabaja durante años en su inacabada tercera novela, además, se encuentra en la imposibilidad de constituirse como sujeto de enunciación; su palabra se ve opacada tanto por la especulación en torno a su ocultamiento voluntario como por la imagen que los medios han construido de él, condenándolo al silencio y a la muerte.

Esta condición del escritor se podría extender, de manera más general, a la del individuo en el mundo contemporáneo que se encontraría entre, por un lado, la dificultad -ver la imposibilidad-de escapar de las apariencias y, por el otro, la opción de emprender una continua fuga que se vería frustrada al no poder hallar lugares sin vigilancia. Ante las alternativas de la hipervisibilidad generalizada y la huida paranoica, se trataría de responder a la necesidad del anonimato con operaciones que no sean un permanente escape o un desaparecer mórbido sino un devenir imperceptible y una forma de presencia en el mundo.

Retomando el ejemplo de la figura del escritor, se podría pensar en una muerte del autor que no sea literalmente el huir paranoico de la transparencia del mundo sino una operación de despersonalización -como ya lo señalaba Roland Barthes ${ }^{4}-\mathrm{o}$, precisamente, una experiencia de la discreción. Como el mismo término lo indica, la discreción es una experiencia intermitente. La etimología de discreción viene del latín discretio que significa discernimiento, separación, distinción; en matemáticas toma el sentido de discontinuo. A partir de esta definición, Pierre Zaoui subraya que no se puede ser continuamente discreto pues la discreción presupone una dialéctica de la aparición y la desaparición, de la exposición y de la reserva.

Siguiendo esta línea de pensamiento que se distancia tanto de la exhibición constante como de la desaparición definitiva, podríamos proponer otro ejemplo y considerar cómo se configuraría la práctica de un artista discreto al diferenciarse de la figura del artista profesional exitoso impelido a producir y a exponer permanentemente o casi simultáneamente, fenómeno que conduce muchas veces a una sobreproducción de lo mismo o a una redundancia de productos derivados. Se trataría, en este caso, de trabajar a un ritmo distinto del impuesto por la exigencia continua de los flujos de la sociedad y del mercado, alternando la visibilidad requerida con momentos de discreción que abrirían, así, la posibilidad de anteponer la presencia del mundo a la visibilidad de la figura del artista y de su producción.

Podríamos relacionar así la necesidad de la discreción con los procesos artísticos y, también, de manera más general, con todo proceso creativo que implique una manera de hacer(se) distinta de las formas establecidas. En el mismo sentido, en Volverse público ${ }^{5}$, Boris Groys plantea la necesidad de mantener los procesos creativos alejados de una mirada pública. Partiendo de la constatación de que Internet es una máquina de vigilancia que crea un campo de visibilidad y transparencia total, Groys señala un problema no en la red como lugar de distribución y exhibición del arte sino en el hecho de que ha permitido borrar la diferencia entre el momento y el lugar de la producción y de la exhibición del trabajo artístico. El acceso a Internet permite exhibir de principio a fin los procesos de producción que antes se desarrollaban

\footnotetext{
${ }^{4}$ Barthes R. La muerte del autor. In: El susurro del lenguaje. Barcelona: Paidós, 1987.

${ }^{5}$ Groys B. Volverse público. Las transformaciones del arte en el ágora contemporánea. Buenos Aires: Caja Negra, 2014.
} 
en los espacios privados; el artista ya no se esconde detrás de su trabajo. Y, esto sería problemático siguiendo la idea de Jean-Paul Sartre quien concibe la mirada de los otros sobre el individuo como impedimento de cambio pues no le permite diferenciarse de la identidad que le ha otorgado la sociedad. Groys plantea la ausencia temporal como constitutiva del trabajo creativo, "es creativo porque tiene lugar más allá del control público, incluso más allá del control que ejerce la conciencia del autor"6, es decir, habría que separar el tiempo del trabajo del tiempo de la exposición para que exista la posibilidad de producir una diferencia, tanto con respecto a sí mismo como con las identidades o modelos asignados.

Subrayemos, nuevamente, la intermitencia como una característica fundamental de la experiencia de la discreción que no es, entonces, ni la transparencia total ni la desaparición definitiva. Además, la discreción no se opone a la reivindicación de la presencia pues, como lo señala Zaoui, "hay momentos macro y micro históricos y lugares geográficos y sociales en los que la visa pasa del lado de la manifestación, del aparecer, de la capacidad de no retirarse y de hacerse escuchar". ${ }^{7}$ Y, en este sentido, el retirarse no es negar ni la propia existencia ni la del mundo sino que constituye una manera de habitarlo.

Podríamos entonces considerar la discreción como parte de una estrategia, como el diseño consiente de una forma de actuar, de marcar un ritmo en las relaciones y de una negociación con las apariencias. La discreción se entiende así en su dimensión política y no como una cualidad moral, a pesar de que, efectivamente, implique anteponer la presencia del mundo al yo. O, como enseñan los mitos: "el mundo está antes que la vida, la vida antes que el hombre, el respeto de los otros antes que el amor propio", escribe Zaoui, retomando la idea de lo que Levi Strauss llamaba una 'deferencia hacia el mundo' ${ }^{8}$

Volviendo sobre la figura del escritor, Zaoui relaciona su concepción de una política de la discreción con los planteamientos propuestos por Maurice Blanchot, el pensador moderno de la literatura como experiencia de la desaparición, en el sentido de que no se puede pensar la creación sin la desaparición del autor, el escritor precisa dejar su lugar vacío para dejar existir las cosas. Se trataría, como en la experiencia de la discreción, de un cierto desapego del mundo para salir de la lucha sin fin por el reconocimiento. Además, Blanchot es el pensador de la comunidad sin comunidad, la comunidad no como una experiencia que hacemos sino como una que nos constituye, es decir, como una experiencia de despersonalización. También, define la amistad como una pasión por el anonimato.

Volvamos sobre las características del individuo moderno para indagar de manera más precisa en la relación que Zaoui establece entre la discreción y la experiencia de la ciudad, a partir de las características del flaneur y de la figura de Baudelaire, retomando la perspectiva de Walter Benjamin. La ciudad es, efectivamente, la condición de la discreción pues esta resulta imposible en los pueblos o en los lugares despoblados. La discreción sería entonces una experiencia, no solo posible sino también necesaria, en las ciudades regidas por la lógica del capitalismo moderno y habitadas por la multitud de seres anónimos.

Es en este contexto que Zaoui sitúa la dimensión política de la discreción, esta consistiría en "saber valerse de astucias ante los mandatos contradictorios del tiempo -ser nadie donde se nos pide ser alguien, ser todos los nombres de la historia donde nos piden no ser más que este alguien"9 y desplazarse así del imperativo de las identidades fijas, ejerciendo el arte de desaparecer entre el anonimato y las multitudes, sin identificarse ni ser identificado.

\footnotetext{
${ }^{6}$ Groys, B. Volverse público. p. 139.

${ }^{7}$ Zaoui, P. La discreción o el arte de desaparecer. Barcelona: Arpa, 2017.

${ }^{8}$ Zaoui, P. La discreción o el arte de desaparecer. Barcelona: Arpa, 2017.

${ }^{9}$ Zaoui, P. La discreción o el arte de desaparecer. Barcelona: Arpa, 2017.
} 
Recordemos que esta era ya la dinámica que Benjamin percibía en la actividad del flaneur, figura encarnada y, al mismo tiempo, simple tránsito por las veredas; presencia y fugacidad.

La idea de valerse de astucias nos remite a los planteamientos de Michel de Certeau en La invención de lo cotidiano ${ }^{10}$, donde propone que el -valerse de- es una operación que corresponde al arte del débil, a las tácticas que el individuo inventa ante las estructuras definidas por las estrategias del poder. Si las estrategias determinan un lugar propio, las tácticas se sirven del tiempo, aprovechan la ocasión, sacan partido de la coyuntura; la apropiación del tiempo se opone a la propiedad de los espacios. Si las estrategias establecen un espacio aprehensible por medio de la visión, las tácticas juegan con lo imprevisible, lo invisible y/o lo efímero para escapar al control.

Podemos afirmar entonces que la política de la discreción está relacionada con una forma de invisibilidad temporal que tiene que ver tanto con la posibilidad de abstraerse de las identidades preestablecidas como con la posibilidad de reapropiarse del tiempo. Entendemos así de manera más precisa por qué puede plantearse como una forma de disidencia con respecto a los parámetros establecidos por las instancias de poder. Retomando los lineamientos de Benjamin frente al apogeo del capitalismo, Zaoui vincula la experiencia de la discreción a la exigencia política de este primero de "no ceder a la reificación de la vida y de inventar nuevas formas de subjetividad". ${ }^{11}$

Esta invención de subjetividades que se distancia de los parámetros definidos por las estrategias del poder, Zaoui la relaciona no solo con un devenir imperceptible sino también con la función de fabulación propuesta por Gilles Deleuze y Félix Guattari ${ }^{12}$, la cual, al romper con modelos prestablecidos del lenguaje, está estrechamente ligada a un devenir menor; es decir, a un uso menor de la lengua, a la articulación con lo político y a una dimensión colectiva.

En relación con el espacio público y la palabra política, Zaoui define dos principios de la experiencia de la discreción. El primero, opondría a una macropolítica que defiende la idea de la transparencia democrática y el acceso de cada cual a la visibilidad, una micropolítica discreta que promueva las formas del anonimato, las zonas de indiscernibilidad, los devenires imperceptibles. Se trataría de subvertir el modelo griego de una visibilidad de todos en el ágora de la cité o del mundo globalizado para plantear, más bien, una sociedad democrática en la que "cada cual puede hacerse visible, ser reconocido en sus derechos y su dignidad y donde cada uno debe retenerse regularmente de serlo para dejar un poco de lugar a los otros y al mundo". ${ }^{13}$ Esto implica, también, cuestionar la división entre lo privado y lo público pues la discreción no puede suceder sino en medio de los otros, así como la vida pública requiere formas de discreción contra la exhibición de su intimidad.

El segundo principio está vinculado con las formas del tiempo y consiste en no esperar para actuar, no esperar "ni el momento oportuno, ni la presencia de los proyectores, ni la aparición de un movimiento o de un acontecimiento. La discreción no depende de la aparición de los seres y las cosas sino que los condiciona". Así, se puede entonces entender la discreción como una forma de acción, como una micropolítica, como un arte de la disimulación, como un devenir imperceptible más que como una alegría simple de no ser visto. En las sociedades de vigilancia generalizada y de saturación de la imagen pública de sí, la discreción, sostiene Zaoui, sería la condición indispensable para todo tipo de compromiso político serio.

Para terminar, el autor señala que su planteamiento sobre la discreción como un arte de desaparecer, como actitud estética y política, no se puede definir conceptualmente de manera completa pues "está constituida por pequeños gestos, posturas ínfimas, miradas y desvíos de miradas". Además, es una cuestión de visión, de construcción de un punto de vista. Es por eso

\footnotetext{
${ }^{10}$ De Certeau, M. La invención de lo cotidiano 1. México: Universidad Iberoamericana, 1999.

${ }^{11}$ Zaoui, P. La discreción o el arte de desaparecer. Barcelona: Arpa, 2017.

${ }^{12}$ Deleuze G. y Guattari F. Kafka, por una literatura menor. México: Era, 1978.

${ }^{13}$ Zaoui, P. La discreción o el arte de desaparecer. Barcelona: Arpa, 2017.
} 
que Zaoui relaciona sus propósitos con el arte, con el trabajo de Blanchot que ya hemos mencionado con respecto a la desaparición del autor como persona o como estatus y la escritura como una experiencia de lo neutro, de lo impersonal. Cita, también, a Cézanne, Kafka o Valéry cuyas obras se opacan como resultados porque importan más sus procesos de realización y producción. Y, finalmente, el arte tendería a desaparecer tal como existe al sobrepasar los modelos en vigencia, al remplazar identidades y clasificaciones por movimiento, búsquedas y devenires. La experiencia de la discreción implica entonces devenir impersonal, desprenderse de sí mismo y de las cosas, contra toda idea de propiedad. Se puede decir también que es una experiencia del espacio discontinuo, con lugares separados, fuera de escena. Además, es una experiencia del tiempo, entendido como devenir y no como sucesión de instantes.

\section{Referencias}

BARTHES, R. La muerte del autor. In: . El susurro del lenguaje. Barcelona: Paidós, 1987.

DE CERTEAU, M. La invención de lo cotidiano 1. México: Universidad Iberoamericana, 1999.

DELEUZE, G. y GUATTARI F. Mil Mesetas. Capitalismo y esquizofrenia. Valencia: PreTextos, 2002.

DELEUZE, G. y GUATTARI F. Kafka: por una literatura menor. México: Era, 1978.

DELILLO, D. Mao II. Barcelona: Seix Barral, 2008.

GROYS, B. Volverse público. Las transformaciones del arte en el ágora contemporánea. Buenos Aires: Caja Negra, 2014.

ZAOUI, P. La discreción o el arte de desaparecer. Barcelona: Arpa, 2017. 